\title{
Modelling of the thermal cycle of a gas engine using AVL FIRE Software
}

\begin{abstract}
Paper presents results of modelling gas engine thermal cycle using AVL FIRE and KIVA 3 V software. There are described three combustion models used in software. KIVA and FIRE software are used in Institute of Internal Combustion Engines and Control Engineering for analysis of thermal cycle of IC engines. FIRE software gives many possibilities with many combustion models. All used combustion models are dependent on turbulence of flow field before ignition. Comparison of modelling results of thermal cycle of IC engine is presented in paper. Pressure, temperature, heat release and turbulence parameters variations in function of crank angle as well as spatial distribution of above mentioned quantities at selected crank angles were determined.
\end{abstract}

Key words: internal combustion engine, thermal cycle, modelling, combustion

\section{Modelowanie obiegu silnika gazowego z wykorzystaniem programu AVL FIRE}

\begin{abstract}
W pracy przedstawiono wyniki modelowania obiegu cieplnego silnika gazowego z wykorzystaniem programy ACL FIRE oraz programu KIVA-3V. Program KIVA oraz FIRE sa programami wykorzystywanymi w Instytucie Maszyn Tłokowych i Techniki Sterowania do modelowania obiegu silnika. Program FIRE daje możliwość użycia wielu podmodeli spalania. Modele te sa $w$ dużej mierze zależne od turbulencji ładunku. Przedstawiono przebiegi zmian ciśnienia, temperatury, wydzielania ciepła oraz parametrów turbulencji w funkcji kąta obrotu wału korbowego oraz przestrzenne rozkłady wybranych parametrów.
\end{abstract}

Słowa kluczowe: silnik spalinowy, obieg cieplny, modelowanie, spalanie

\section{Introduction}

The numerical simulations with advanced computer programs gives possibilities to very complicated processes research conduct. In 2009 Institute of Internal Combustion Engines and Control Engineering began University Partnership Program with AVL Company and to modelling thermal cycle of IC engines using AVL FIRE software. Connection advanced programs with contemporary computers give a chance to modelling turbulent flow and heat processes with combustion, fuel injection, heat transfer, toxic components of exhaust gas and soot. In spite of this, models are still incomplete which require many values taken from experiment. Numerical simulations in additional allow researchers to observe spatial distribution of individual parameters. This make easier to understand a very complicated processes. Mathematical modelling gives possibilities to optimization shape of an intake manifold, an exhaust or a combustion chamber. This method is an essential method in design and optimization. The paper presents results of combustion process modelling in spark ignition test engine Deutz 1650 $\mathrm{cm}^{3}$. Modelling was carried out using three-dimensional CFD: AVL FIRE and KIVA-3V.

\section{AVL FIRE programe characteristic}

The AVL FIRE software belongs to contemporaries programs which are used to modelling of thermal cycle of internal combustion engines. FIRE allows modelling flow and thermal processes occur in the intake manifold, in combustion chamber of IC engine and exhaust pipe with a catalyst and a particulate filter. This programme enables the calcula-

\section{Wstęp}

Modelowe numeryczne z wykorzystaniem coraz bardziej zaawansowanych programów komputerowych umożliwia relatywnie niskim kosztem prowadzić badania bardzo skomplikowanych procesów. Instytut Maszyn Tłokowych i Techniki Sterowania od 2009 roku, w ramach University Partnership Program z firmą AVL, do modelowania obiegu cieplnego silnika tłokowego wykorzystuje program AVL FIRE. Połączenie tak zaawansowanych programów komputerowych z możliwościami obliczeniowymi współczesnych komputerów daje możliwości modelowania turbulentnych procesów cieplno-przepływowych ze spalaniem, wtryskiem paliwa, wymianą ciepła oraz mechanizmami tworzenia się toksycznych składników spalin i sadzy. Mimo to, są to ciągle modele niekompletne, wymagające szeregu wartości wielkości wejściowych zaczerpniętych z eksperymentu. Modelowanie w układzie 3D daje dodatkowo możliwość obserwacji poszczególnych parametrów w czasoprzestrzeni, co znacznie ułatwia poznanie często bardzo złożonych zjawisk. Modelowanie takie daje możliwość optymalizacji kształtu układu dolotowego, wydechowego czy komory spalania. Jest to metoda nieodzowna w procesie projektowania i optymalizacji.

W prezentowanej pracy przedstawiono wyniki modelowania procesu spalania w badawczym silniku o zapłonie iskrowym Deutz $1650 \mathrm{~cm}^{3}$. Modelowanie przeprowadzono przy użyciu wykorzystywanych w IMTiTS Politechniki Częstochowskiej, nowoczesnych programów do modelowania trójwymiarowego CFD: AVL FIRE oraz KIVA-3V. 
tion of transport phenomena, mixing, ignition and turbulent combustion in internal combustion engine. Homogeneous and inhomogeneous combustion mixtures in spark ignition and compression ignition engine can be modelled using this software as well. Kinetics of chemical reactions phenomena is described by combustion models which take oxidation processes in high temperature into consideration. Several models apply to auto ignition processes. AVL FIRE allows modelling knock process which occurs in combustion chamber of IC engine. In fifth models, with different complication level, are taken an influence of turbulence intensity on combustion rate into consideration. The choice depends on modelled object or calculation possibilities. User can use several combustion models: Eddy Breakup Model, Turbulent Flame Speer Closure Model, Cohorent Flame Model, PDF Model, NO formation models: Extendend Zeldovich Models, Heywood Models, soot formation and oxidation models: Lund Flamelet, Frolov Kinetic, Kennedy/Hiroyasu/Magnussen, turbulence models: k-epsilon, k-zeta-f, laminar, LES, ignition models: Diesel, Diesel Multiple Ignition Location, HCCI, Knock (Shell Model), Knock (Shell Model with temperature coupling), AnB Knock, Empirical Knock Model, Diesel ignited gas engine, complex fuel spray models and others. There is reach library of fuels like petrol, diesel and hydrogen or DME. This program allows building three-dimensional computational greed, characterise of boundary conditions of surfaces and initial conditions of simulation. The postprocessor gives possibility to visualization of results. AVL FIRE version 2009 include FIRE ESE Diesel module which was designed for modelling diesel combustion chambers. Injector is modelled as element which takes place inside the combustion chamber. The shape of combustion chamber and tip of injector can be freely shaped. The project of combustion chamber can be imported from others CAD programs. FIRE allows importing meshes form many specialist programs. In Institute of Internal Combustion Engines and Control Engineering computational mesh is generated by ICEM CFD software. FIRE allows take boundary layer into consideration.

\section{Combustion models in AVL FIRE}

Two models were taken into account: Eddy Breakup Model (EBM) and Turbulent Flame Speed Closure Model (TFSCM) [3]. In both models the oxidation processes of a fuel with air is determined by turbulent processes which occurs in combustion chamber. Combustion process is described by a single step irreversible reaction:

$$
\begin{aligned}
& 1 \mathrm{~kg}\left[\mathrm{C}_{\mathrm{n}} \mathrm{H}_{\mathrm{m}} \mathrm{O}_{\mathrm{k}}\right]+\mathrm{S} \mathrm{kg}\left[\mathrm{a}_{1} \mathrm{O}_{2}+\mathrm{a}_{2} \mathrm{~N}_{2}\right] \\
& \Rightarrow(1+\mathrm{S}) \mathrm{kg}\left[\mathrm{a}_{3} \mathrm{CO}_{2}+\mathrm{a}_{4} \mathrm{H}_{2} \mathrm{O}+\left(1-\mathrm{a}_{3}-\mathrm{a}_{4}\right) \mathrm{N}_{2}\right]
\end{aligned}
$$

where: $a_{1}, a_{2}, a_{3}, a_{4}, S-$ dimensionless coefficients for reactions.

\subsection{Eddy breakup model (EBM)}

The Eddy Breakup Model (EBM) [3] represents models which are based on turbulent mixing mechanism. This type was described by Magnussen, Hjertegar and Spalding. This model assumes that a turbulent flame, fuel and oxygen are

\section{Charakterystyka programu AVL FIRE}

Program AVL FIRE [3] należy do najnowocześniejszych narzędzi wykorzystywanych w modelowaniu obiegu cieplnego tłokowego silnika spalinowego. Program FIRE daje możliwość modelowania procesów cieplno-przepływowych począwszy od układu dolotowego przez komorę spalania silnika aż do układu wydechowego z katalizatorem i filtrem cząstek stałych. Program AVL FIRE umożliwia obliczanie zjawisk transportu, mieszania, zapłonu i turbulentnego spalania w silniku tłokowym o spalaniu wewnętrznym. Modelować można spalanie zarówno mieszanek homogenicznych przygotowanych w komorze spalania jak i mieszanek heterogenicznych (niehomogenicznych) utworzonych przez wtrysk paliwa do komory, ponadto obliczenia moga dotyczyć silnika o zapłonie iskrowym albo silnika wysokoprężnego. W programie AVL FIRE kinetyka zjawisk chemicznych jest opisana przez modele spalania uwzględniające procesy utleniania w wysokiej temperaturze. Kilka dostępnych modeli dotyczy analizy samozapłonu paliw węglowodorowych. W modelach tych możliwe jest połączenie schematu utleniania paliwa $\mathrm{w}$ wysokiej temperaturze $\mathrm{z}$ samozapłonem $\mathrm{w}$ silniku wysokoprężnym.

AVL FIRE umożliwia modelowanie zjawiska spalania stukowego w silniku tłokowym. Modele spalania stukowego opisują procesy stuku uwzględniające zużycie paliwa i tworzenie się gorących ognisk samozapłonu ładunku. Wpływ turbulencji na szybkość reakcji tworzenia i spalania mieszanki palnej jest uwzględniony w pięciu dostępnych modelach spalania o różnym stopniu złożoności. Wybór zależy od obiektu modelowania, potrzeby wnikliwości analizy zjawiska oraz możliwości obliczeniowych.

Użytkownik dostaje możliwość wykorzystania najnowszych modeli spalania (m.in. Eddy Breakup Model, Turbulent Flame Speer Closure Model, Cohorent Flame Model, PDF Model i inne), modeli tworzenia się toksycznych składników spalin (m.in. Extendend Zeldovich Models, Heywood Models), modeli tworzenia się cząstek sadzy (m.in. Lund Flamelet, Frolov Kinetic, Kennedy/Hiroyasu/Magnussen), kilku modeli turbulencji (m.in. k-epsilon, k-zeta-f, laminar, LES), szereg modeli zapłonu i samozapłonu (m.in. Diesel, Diesel Multiple Ignition Location, HCCI, Knock (Shell Model), Knock (Shell Model with temperature coupling), AnB Knock, Empirical Knock Model, Diesel ignited gas engine), bardzo rozbudowane modele rozwiązywania zagadnień wtrysku paliwa i inne. Użytkownik dostaje także dużą bibliotekę paliw od tradycyjnych jak benzyna, olej napędowy, przez najczęściej spotykane paliwa gazowe po wodór i DME.

Program pozwala na stworzenie trójwymiarowej siatki przestrzeni obliczeniowej, określenie warunków brzegowych poszczególnych powierzchni oraz warunków początkowych symulacji oraz wizualizację otrzymanych wyników w bogato wyposażonym postprocesorze. Użyteczną funkcją jest możliwość śledzenia online większości obliczanych parametrów w czasie działania solvera. Wersja FIRE 2009 ma moduł Fire ESE Diesel przeznaczony do modelowania komory spalania silnika o zapłonie samoczynnym. Wtryskiwacz jest modelowany jako element fizyczny występujący w komorze spalania. Kształt komory spalania oraz końcówki wtryskiwacza można w dowolny 
situated in the same eddies which are separated from eddies containing hot combustion products.

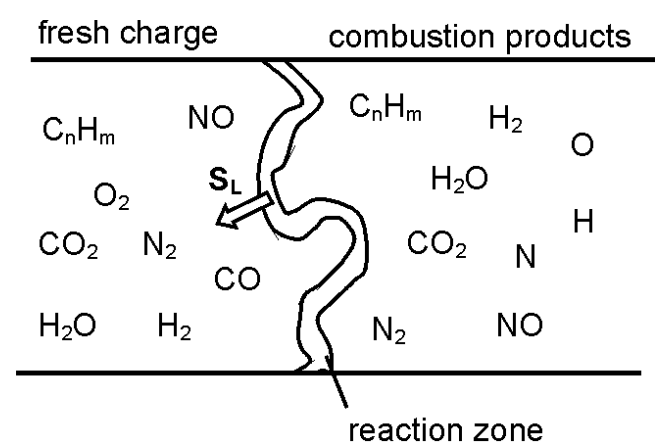

Fig. 1. Idea of turbulent combustion model Rys. 1. Idea turbulentnego modelu spalania

In the worked out by Magnusen model the results mainly depends on turbulent field of fresh charge parameters. The rate of combustion is determined by the rate of intermixing on the smallest scales of eddies containing fuel and oxygen. This is determined by the rate of dissipation of eddies. The rate of chemical reactions depends on an initial kinetic energy and turbulent length scale as well. The time scales of the chemical reactions are very short compared with the scales which determine turbulent transport processes. The mean rate of the chemical reaction can be described as:

$$
\omega_{\mathrm{fu}}=\frac{\mathrm{C}_{\mathrm{fu}}}{\tau_{\mathrm{R}}} \bar{\rho} \min \left(\overline{\mathrm{y}}_{\mathrm{fu}}, \frac{\overline{\mathrm{y}}_{\mathrm{Ox}}}{\mathrm{S}}, \frac{\mathrm{C}_{\mathrm{Pr}} \overline{\mathrm{y}}_{\mathrm{Pr}}}{1+\mathrm{S}}\right)
$$

where: $\mathrm{C}_{\mathrm{fu}}, \mathrm{C}_{\mathrm{Pr}}$ - empirical coefficients, $\tau_{\mathrm{R}}$-turbulent mixing time scale for reaction, $\rho$-density, $\bar{y}_{f u}$ - fuel mass fraction, $\bar{y}_{\mathrm{O}_{2}}$ - oxygen mass fraction, $\overline{\mathrm{y}}_{\mathrm{Pr}}$ - hot product mass fraction, $\mathrm{S}$ - stoichiometric oxygen requirement.

The first two quantities of the "minimum" operator determine whether the reactants are presents in adequate quantity to occur chemical reaction. Third of them determine reaction probability. This ensures that the flame is not spread without hot products. $\mathrm{C}_{\mathrm{fu}}$ and $\mathrm{C}_{\mathrm{Pr}}$ are empirical coefficients, $\tau_{\mathrm{R}}$ is the turbulent mixing time scale for reaction. Coefficient $\mathrm{C}_{\mathrm{fu}}$ depends on turbulence and fuel parameters. This parameter requires adjustment with respect to experimental combustion data from real engine. The general assumption is that the rate of combustion processes depend on the intermixing rate occurs in molecular scales, in eddies containing reactants and hot products and eddies formed in results of dissipation process. The advantage of this model is its simplicity, which do not involve knowledge of many parameters of chemical reactions. In this model, worked out by Magnusen, the results mainly depends on turbulent field of fresh charge parameters like initial turbulent kinetic energy and turbulent time and length scales.

\subsection{Turbulent flame speed closure model (TFSCM)}

The Turbulent Flame Speed Closure Model is destined for modelling combustion processes of homogeneous and inhomogeneous mixtures in spark ignition engine. The essence of this model is the determination of rate of chemical sposób kształtować. Kształt komory spalania można także importować $\mathrm{z}$ innych programów typu CAD. Do programu FIRE można importować siatki obliczeniowe stworzone w innych specjalistycznych programach. W Instytucie Maszyn Tłokowych i Techniki Sterowania do tworzenia siatek obliczeniowych wykorzystuje się program ICEM CFD. Program pozwala na uwzględnienie w obliczeniach warstwy przyściennej o zadeklarowanych przez użytkownika parametrach.

\section{Modele spalania programu AVL FIRE}

W programie AVL FIRE wykorzystano dwa modele spalania: Eddy Breakup Model (EBM) i Turbulent Flame Speed Closure Model (TFSCM) [3]. W modelach tych złożony proces utleniania paliw węglowodorowego w powietrzu, z precyzyjnym odzwierciedleniem procesu turbulentnego spalania, opisany jest przez pojedynczą reakcję nieodwracalną (1), gdzie: $\mathrm{a}_{1}, \mathrm{a}_{2}, \mathrm{a}_{3}, \mathrm{a}_{4}, \mathrm{~S}$ - bezwymiarowe współczynniki stechiometryczne dla danej reakcji.

\subsection{Eddy Breakup Model (EBM)}

Model (EBM) [3] jest przedstawicielem modeli spalania opartych na mechanizmie mieszania turbulentnego, przedstawionego przez Magnussena, Hjertegera i Spaldinga. W modelu zakłada się, że turbulentny płomień, reaktanty - paliwo i tlen są zawarte w tej samej strukturze wirowej oraz że są oddzielone od struktur zawierających gorące produkty spalania.

W modelu opracowanym przez Magnussena, rezultaty zależą głównie od parametrów pola turbulencji ładunku. Szybkość reakcji zależy zarówno od początkowej energii kinetycznej turbulencji jak i od turbulentnej skali długości.

Skale czasowe reakcji chemicznych są dużo mniejsze od skali czasowych charakteryzujących proces turbulentnego transportu. Szybkość reakcji chemicznych jest determinowana przez wzajemne mieszanie się struktur wirowych na poziomie skal molekularnych, czyli przez szybkość dyssypacji struktur wirowych. Średnia szybkość reakcji może być przedstawiona przez zależność (2),

gdzie: $\mathrm{C}_{\mathrm{fu}}, \mathrm{C}_{\mathrm{Pr}}-$ współczynniki empiryczne, $\tau_{\mathrm{R}}-$ skala czasowa reakcji, $\rho$ - gęstość, $\bar{y}_{f u}$ - udział masowy paliwa, $\overline{\mathrm{y}}_{\mathrm{O}_{2}}$ - udział masowy tlenu, $\overline{\mathrm{y}}_{\mathrm{Pr}}-$ udział masowy produktów spalania, $\mathrm{S}$ - stechiometryczny współczynnik spalania.

Pierwsze dwie wielkości w warunku ,min” ustalają czy paliwo i tlen są obecne w dostatecznej ilości aby reakcja przebiegła, trzeci wyraz określa prawdopodobieństwo zachodzenia reakcji chemicznych czyli zapewnia, że płomień nie rozprzestrzenia przy braku gorących produktów. $\mathrm{C}_{\mathrm{fu}} \mathrm{i}_{\mathrm{Pr}_{\mathrm{r}}}$ są współczynnikami empirycznymi, $\tau_{\mathrm{R}}$ jest skalą czasową mieszania turbulentnego dla zachodzących reakcji. Współczynnik $\mathrm{C}_{\text {fu }}$ zależy od parametrów paliwa oraz od parametrów turbulencji ładunku. Współczynnik ten wymaga wyznaczenia na podstawie wyników spalania w rzeczywistym silniku.

Można zatem założyć, że o szybkości spalania decyduje szybkość wzajemnego wymieszania się w skali cząsteczkowej wirów zawierających substraty i gorące produkty oraz wirów utworzonych w wyniku procesu rozproszenia-dyssypacji. Atrakcyjność modelu polega na tym, że nie wymaga on znajomości szeregu zmiennych reakcji procesu utleniania paliwa węglowodorowego. 
reactions depending on fresh charge turbulence parameters in the cylinder of internal combustion engine. The turbulence intensity and turbulence scales of charge have significant impact on combustion process. These parameters have influence on fire structure like the flame thickness and flame spread. The rate of chemical reaction is described by two mechanisms: first - auto ignition model (AI) and second flame propagation scheme (FP).

The first one is described by Arrhenius equation. In the second mechanism the flame propagation mainly depends on the turbulent flame speed. Depending on conditions one of these mechanisms is the dominant one. The fuel reaction rate can be described by operator:

$$
\omega_{\mathrm{fu}}=\max \left(\text { Auto }- \text { ign } \omega_{\mathrm{AI}} \text {, FlameP ropagation } \omega_{\mathrm{FP}}\right)
$$

The first mechanism was constructed for combustion air factor 0.5 to 0.65 and pressure from 0.3 to $12 \mathrm{MPa}$. The rate of auto ignition reaction is described by:

$$
\omega_{A I}=a_{1} \rho^{a_{2}} y_{\text {fuel }}^{a_{3}} y_{O_{2}}^{a_{4}} T^{a_{5}} \exp \left(-\frac{T_{a}}{T}\right)
$$

where: $\mathrm{a}_{1}, \ldots, \mathrm{a}_{5}-$ empirical coefficients, $\mathrm{T}_{\mathrm{a}}$ - activation temperature, $\mathrm{T}$ - temperature, $\rho$ - density, $\mathrm{y}_{\mathrm{fu}}$ - fuel mass fraction, $\mathrm{y}_{\mathrm{O} 2}$ - oxygen mass fraction.

In the second mechanism, the reaction rate $\omega_{\mathrm{FP}}$ is described by gas density, turbulent combustion speed $\mathrm{S}_{\mathrm{t}}$ and gradient of mass fraction $\nabla y_{\text {fuel }}$.

$$
\omega_{\mathrm{FU}}=\rho \mathrm{S}_{\mathrm{T}} \nabla_{\mathrm{y}} \text { fuel }
$$

Initially this model had been worked out for homogenous premixed combustion mixtures, next was adapted to inhomogeneous charges. Previous relationship which described reaction rate $\omega_{\mathrm{FP}}$ was written as the product of the gas density, fuel mass fraction gradient and the turbulent burning velocity.

$$
\omega_{\mathrm{FP}}=\rho \mathrm{S}_{\mathrm{T}} \nabla \mathrm{cf} \mathrm{st}_{\mathrm{st}}
$$

This approach was described for homogeneous premixed combustion mixtures and near-wall treatment of the reaction rate. Small eddies of fresh charge and the other motions of fluid cause increase of the flame front. The flame surface increase cause increase of combustion rate of air-fuel mixture. The high turbulence level which cause of the high flame propagation rate in internal combustion engine can be achieved by squish effect and the suitable shape of the combustion chamber.

\section{Combustion model in KIVA 3V}

Numerical researches were conducted using also KIVA$3 \mathrm{~V}$ software. The engine work cycle model in the code is based on system of mass, momentum and energy conservation equations describing three dimensional, unsteady flow field with chemical reactions (combustion). The code solves three dimensional Navier-Stokes equations for the mixture of compressible liquids, which enables taking into account creation and development of shock wave in gas. Periodic
W modelu opracowanym przez Magnussena, rezultaty zależą głównie od parametrów pola turbulencji ładunku. Szybkość reakcji zależy zarówno od początkowej energii kinetycznej turbulencji jak i od turbulentnej skali długości.

\subsection{Turbulent flame speed closure model (TFSCM)}

Model TFSC [3] jest przeznaczony do modelowania procesu spalania homogenicznych mieszanek w silniku o zapłonie iskrowym. Istotą modelu jest wyznaczenie stopnia reakcji w zależności od parametrów turbulencji ładunku znajdującego się w cylindrze silnika.

O procesie spalania w znaczący sposób decyduje intensywność turbulencji i skala turbulencji ładunku, które to wpływają na strukturę płomienia czyli grubość frontu płomienia oraz prędkość jego rozprzestrzeniania się. Szybkość reakcji chemicznych jest określana przy pomocy dwóch mechanizmów: jeden to zapłon samoczynny (auto-ignition, AI) a drugi to mechanizm rozprzestrzeniania się płomienia (FP). Pierwszy jest opisany równaniem Arrheniusa a w drugim mechanizmie propagacja płomienia zależy przede wszystkim od szybkości spalania turbulentnego. W zależności od warunków fizyko-chemicznych jeden z tych mechanizmów jest dominujący (3).

Pierwszy mechanizm jest wykorzystywany dla współczynników nadmiaru powietrza od 0,5 do 0,65 i ciśnień od 0,3 do $12 \mathrm{MPa}$. Szybkość kinetycznej reakcji samozapłonu określona jest zależnością (4),

gdzie: $\mathrm{a}_{1}, \ldots, \mathrm{a}_{5}-$ współczynniki empiryczne, $\mathrm{T}_{\mathrm{a}}$ - temperatura aktywacji, $\mathrm{T}$ - temperatura, $\rho$ - gęstość, $\mathrm{y}_{\mathrm{fu}}$ - udział masowy paliwa, $\mathrm{y}_{\mathrm{O} 2}$ - udział masowy tlenu.

$\mathrm{W}$ drugim mechanizmie, szybkość reakcji $\omega_{\mathrm{FP}}$ jest opisana jako efekt gęstości gazów, prędkości spalania turbulentnego $\mathrm{S}_{\mathrm{t}}$ oraz gradientu udziału masowego paliwa $\nabla \mathrm{y}_{\text {fuel }}$ (5).

Takie podejście było początkowo zastosowane do opisu procesu spalania mieszanek homogenicznych. Następnej kolejności model ten zastosowano także do opisu procesów spalania mieszanek niehomogenicznych. Poprzednia zależność na szybkość $\omega_{\mathrm{FP}}$ uległa pewnym zmianom. Gradient masy cząsteczkowej paliwa został zastąpiony przez funkcję zmian reakcji w mieszance stechiometrycznej (6).

To podejście mogło zostać wykorzystane przy analizie spalania mieszanek homogenicznych $i$ wyznaczaniu szybkości reakcji w warstwie przyściennej. W transporcie płomienia biorą udział małe zawirowania świeżego ładunku oraz pozostałe ruchy towarzyszące procesowi turbulencji co powoduje znaczący wzrost powierzchni frontu płomienia. Wzrost powierzchni frontu płomienia powoduje wzrost szybkości spalania mieszaniny paliwowo-powietrznej. Wysoki poziom turbulencji a przez to wysoką efektywną szybkość propagacji płomienia w silniku tłokowym może być osiągnięta przez tzw. squish oraz odpowiedni kształt komory spalania.

Program FIRE jest programem komercyjnym dla którego $\mathrm{w}$ dostępnej literaturze nie znaleziono dokładniejszego opisu zastosowanych algorytmów obliczeniowych.

\section{Model spalania programu KIVA-3V}

Badania numeryczne były prowadzone $\mathrm{z}$ wykorzystaniem programu KIVA-3V. Model KIVA-3V bazuje na rozwiązywaniu równań zachowania masy, pędu, energii i 
boundary conditions and walls (with turbulent wall law, free slide and without slide, with adiabatic wall and with diversified temperature distribution on the wall) are used as boundary conditions in the KIVA-3V code. Three turbulence models are implemented: $\kappa-\varepsilon, \mathrm{RNG} \kappa-\varepsilon$ and SGS (Sub-Grid Scale).

The combustion submodel consists of four kinetic and six equilibrium reactions. The kinetic reactions are: one global reaction (oxidation of hydrocarbon fuel $\mathrm{C}_{n} \mathrm{H}_{\mathrm{m}}$ ) with extended Zeldovich mechanisms for $\mathrm{NO}_{\mathrm{x}}$ formation. The rate of equilibrium reaction doesn't depend on time and depends only on temperature.

$$
\begin{gathered}
\mathrm{C}_{\mathrm{n}} \mathrm{H}_{\mathrm{m}}+\mathrm{O}_{2} \stackrel{\mathrm{k}_{\mathrm{r}}}{\Rightarrow} \mathrm{CO}_{2}+\mathrm{H}_{2} \mathrm{O} \\
\mathrm{O}+\mathrm{N}_{2} \Leftrightarrow \mathrm{NO}+\mathrm{N} \\
\mathrm{N}+\mathrm{O}_{2} \Leftrightarrow \mathrm{NO}+\mathrm{O} \\
\mathrm{N}+\mathrm{OH} \Leftrightarrow \mathrm{NO}+\mathrm{H}
\end{gathered}
$$

The equilibrium reactions are:

$$
\begin{gathered}
\mathrm{H}_{2} \Leftrightarrow 2 \mathrm{H} \\
\mathrm{O}_{2} \Leftrightarrow 2 \mathrm{O} \\
\mathrm{N}_{2} \Leftrightarrow 2 \mathrm{~N} \\
\mathrm{O}_{2}+\mathrm{H}_{2} \Leftrightarrow 2 \mathrm{OH} \\
\mathrm{O}_{2}+2 \mathrm{H}_{2} \mathrm{O} \Leftrightarrow 4 \mathrm{OH} \\
\mathrm{O}_{2}+2 \mathrm{CO} \Leftrightarrow 2 \mathrm{CO}_{2}
\end{gathered}
$$

The kinetic reaction proceeds at a rate of $\dot{\omega}_{\mathrm{r}}$ given by:

$$
\dot{\omega}_{\mathrm{r}}=\mathrm{k}_{\mathrm{r}} \prod\left[\frac{\rho_{\mathrm{i}}}{\mathrm{M}_{\mathrm{i}}}\right]^{\mathrm{a}_{\mathrm{i}}}=\mathrm{k}_{\mathrm{r}}\left[\mathrm{C}_{\mathrm{n}} \mathrm{H}_{\mathrm{m}}\right]^{\mathrm{a}_{1}}\left[\mathrm{O}_{2}\right]^{\mathrm{a}_{2}}
$$

where: $k_{r}$ - rate coefficient for reaction, $\rho_{i}$ - mass density of species $\mathrm{i}, \mathrm{M}_{\mathrm{i}}-$ molecular weight of species $\mathrm{i}, \mathrm{a}_{1}, \mathrm{a}_{2}$ - integer stoichiometric coefficients for reaction.

Rate coefficients for reaction are assumed to be of a generalized Arrhenius from:

$$
\mathrm{k}_{\mathrm{r}}=\mathrm{A}_{\mathrm{r}} \mathrm{T}^{\mathrm{r}} \exp \left(-\mathrm{E}_{\mathrm{r}} / \mathrm{T}\right)
$$

where: $A_{r}$ - constant, $E_{r}$ - activation energy, $T$ - temperature.

\section{Research object}

The research object was a spark ignition engine powered by gas fuel. This is test engine which was adapted from two cylinders compression ignition engine DEUTZ. As a result of the reconstruction was adaptation of this engine to combustion of methane and decreased compression ratio to 8 .

Figure 2 shows cross-section of cylinder of the test engine with asymmetrical placed sparking plug. ilości składników, opisujących nieustalone, trójwymiarowe pole przepływu z reakcją chemiczną (spalaniem).

W podmodelu reakcji chemicznych procesu spalania paliwa węglowodorowego uwzględniono cztery reakcje kinetyczne i sześć reakcji równowagowych. Pierwsza reakcja kinetyczna określa utlenianie paliwa $\left(\mathrm{C}_{\mathrm{n}} \mathrm{H}_{\mathrm{m}}\right)$. Kolejne trzy opisują, zgodnie z rozszerzonym modelem Zeldowicza, mechanizm tworzenia tlenku azotu. Dla reakcji kinetycznych szybkość przebiegu reakcji chemicznych w czasie jest określana przez zastosowanie wyrażenia typu Arrheniusa. Dla reakcji równowagowych przebieg reakcji nie jest zależny od czasu, a ilość substratów i produktów zależy jedynie od stałej równowagi reakcji zależnej z kolei jedynie od temperatury [1] (7)-(16).

Dla dowolnego węglowodoru szybkość ogólnej reakcji chemicznej (spalania) (17),

gdzie: $\mathrm{k}_{\mathrm{r}}$ - współczynnik szybkości przebiegu reakcji, $\rho_{\mathrm{i}}$ - gęstość i-tego składnika, $\mathrm{M}_{\mathrm{i}}$ - masa cząsteczkowa i-tego składnika, $\mathrm{a}_{1}, \mathrm{a}_{2}$ - bezwymiarowe współczynniki stechiometryczne dla określonej reakcji.

Współczynnik szybkości reakcji kinetycznych ma ogólną postać określoną wyrażeniem Arrheniusa (18), gdzie: $A_{r}$ - stała, $E_{r}$ - energia aktywacji, $\mathrm{T}$ - temperatura.

\section{Obiekt modelowania}

Obiektem badań jest silnik z zapłonem iskrowym zasilany paliwem gazowym. Jest to silnik badawczy, który powstał na bazie dwucylindrowego silnika wysokoprężnego Deutz. W wyniku zmian konstrukcyjnych zastosowano w silniku zapłon iskrowy i przystosowano silnik do pracy na metanie, zmieniono kształt komory spalania co doprowadziło do zmniejszenia stopnia sprężania do wartości 8.

Na rys. 2 przedstawiono przekrój cylindra silnika badawczego z niesymetrycznie umieszczoną świecą zapłonową.

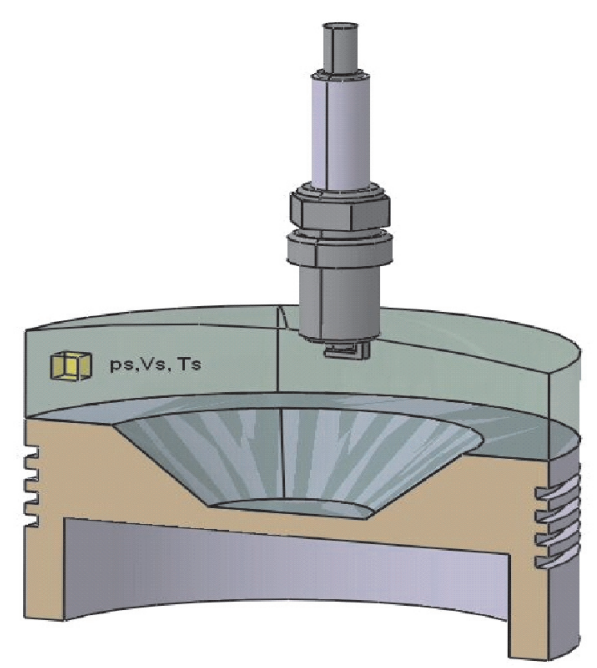

Fig. 2. Combustion chamber of the modeled engine [7] Rys. 2. Komora spalania silnika badawczego [7]

\section{Modelowanie obiegu silnika badawczego}

Modelowanie w programie AVL FIRE oraz KIVA-3V zostało przeprowadzone dla paliwa gazowego - metanu, dla tych samych warunków brzegowych i początkowych. We 
Table 1. Main engine parameters

Tabela 1. Podstawowe parametry silnika

\begin{tabular}{|l|c|}
\hline Compression ratio/stopień sprężania & 8 \\
\hline Stroke/skok tłoka & $105 \mathrm{~mm}$ \\
\hline Cylinder diameter/średnica cylindra & $100 \mathrm{~mm}$ \\
\hline Engine cubic capacity/pojemność skokowa & $825 \mathrm{~cm}^{3}$ \\
\hline Number of cylinders/liczba cylindrów & 2 \\
\hline Direction of cylinders/układ cylindrów & vertical/pionowy \\
\hline Length of connecting-rod/dlugość korbowodu & $136 \mathrm{~mm}$ \\
\hline Rotational speed/prędkość obrotowa & $1500 \mathrm{rpm}$ \\
\hline
\end{tabular}

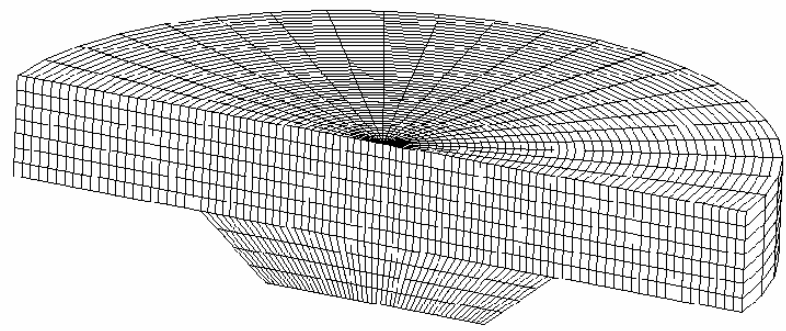

wszystkich przypadkach wykorzystano model turbulencji $\kappa-\varepsilon[3]$.

Siatka obliczeniowa komory spalania silnika badawczego skonstruowana w preprocesorach obu programów była zbliżona i składała się z podobnej liczby komórek i węzłów.

Model zapłonu mieszanki paliwowo-powietrznej wymaga podania kąta OWK wystąpienia zapłonu, objętości obszaru występowania zapłonu wraz z jego położeniem wewnątrz komory spalania. Program daje możliwość modelowania zapłonu wielopunktowego oraz umożliwia uaktywnienie podmodeli spalania stukowego.

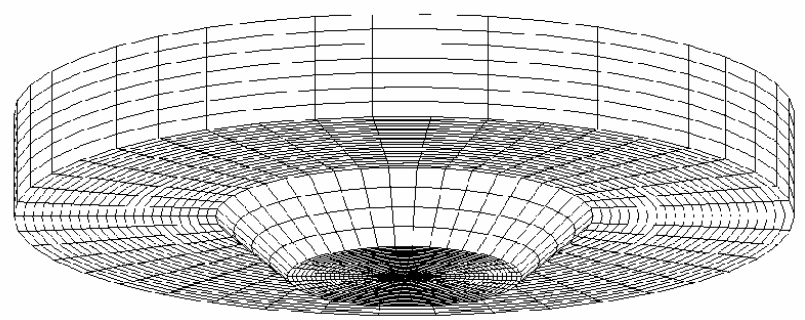

Fig. 3. Geometric mesh of combustion chamber at TDC Rys. 3. Siatka komory spalania modelowanego silnika w GMP ttoka

\section{Modelling of thermal cycle of test engine}

Modelling in AVL FIRE and KIVA-3V software was conduct for gas fuel - methane, for these same boundary and initial conditions. In both cases was used k-e turbulence model. The computational mesh of combustion chamber of test engine in both cases was made of this same number of cells and nodes.

The model of fuel-air mixture ignition requires of ignition crank angle occurrence, volume of ignition area and its location inside combustion chamber. There is possibility to model multi spark plug ignition and allows modelling combustion knock process.

Calculation starts in BDC at the beginning of compression stroke for these same starting conditions and finished 180 degree after TDC. Calculations were conduct for combustion air factor equal 1.0 and ignition crank angle equal 10 degree before TDC.

\section{Results of calculations}

A number of characteristic quantities of combustion process in the test engine were obtained as a result of numerical analysis. Chosen quantities courses are presented at mentioned below figures. Pressure courses in the analyzed engine are presented in figure 4 . In both cases for FIRE and KIVA-3V the compression pressure achieved this same value. Results of modeling in KIVA-3V code and AVL FIRE using Eddy Breakup model achieved almost the same course. TFSC model used in AVL FIRE was caused bigger differences in the maximum peak of pressures. Combustion process in this case proceeded relatively slowly.

The heat release and heat release rate courses are presented in Fig. 5. TFSC model in analysed case gave the big-
Obliczenia rozpoczynały się w DMP na początku suwu sprężania trwały przez $360^{\circ} \mathrm{OWK}$ do zakończenia suwu pracy silnika. Obliczenia prowadzono dla współczynnika nadmiaru powietrza: 1,0 i kąta wyprzedzenia zapłonu $10^{\circ}$ OWK przed GMP.

Table 2. Chosen input parameters of modelled process

Tabela 2. Wybrane parametry wejściowe modelowanego procesu

\begin{tabular}{|l|c|}
\hline Ignition timing/kąt wyprzedzenia zapłonu & $\begin{array}{c}10^{\circ} \text { before TDC/ } \\
10^{\circ} \text { przed GMP }\end{array}$ \\
\hline $\begin{array}{l}\text { Combustion air factor/wspótczynnik nadmiaru } \\
\text { powietrza }\end{array}$ & 1.0 \\
\hline $\begin{array}{l}\text { Initial temperature/temperatura mieszanki na } \\
\text { początku sprężania }\end{array}$ & $293 \mathrm{~K}$ \\
\hline $\begin{array}{l}\text { Initial pressure/ciśnienie mieszanki na począt- } \\
\text { ku sprężania }\end{array}$ & $0.9 \mathrm{bar}$ \\
\hline \begin{tabular}{l} 
Fuel/paliwo \\
\hline $\begin{array}{l}\text { Turbulence kinetic energy (180 before BDC)/ } \\
\text { energia kinetyczna turbulencji (180 przed } \\
\text { GMP) }\end{array}$
\end{tabular} & $0.1 \mathrm{~J} / \mathrm{m}^{3}$ \\
\hline $\begin{array}{l}\text { Turbulence length scale }\left(180^{\circ} \text { before BDC)/ }\right. \\
\text { skala turbulencji (180 przed GMP) }\end{array}$ & $1.12 \mathrm{~cm}$ \\
\hline
\end{tabular}

\section{Wyniki modelowania}

W wyniku analizy numerycznej uzyskano szereg wielkości charakteryzujących proces spalania w silniku badawczym. Przebiegi wybranych wielkości w funkcji zależności od kąta obrotu wału korbowego przedstawiono na poniższych rysunkach.

Na rysunku 4 przedstawiono przebieg ciśnienia. Ciśnie nie sprężania osiągało te same wartości dla obydwu pro- 
gest heat release. Heat release in this case was characterised by long time duration. Results obtained from KIVA-3V code were characterised by smaller heat release but heat release rate occurs faster.

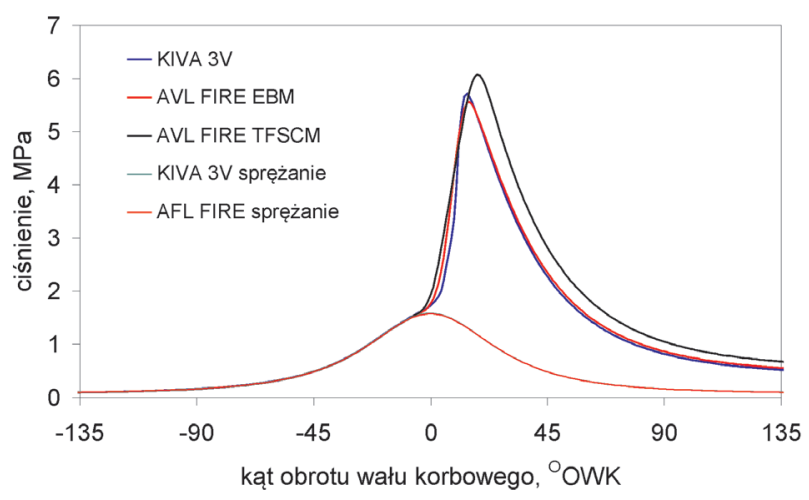

Fig. 4. In cylinder pressure courses Rys. 4. Przebieg zmian ciśnienia w cylindrze

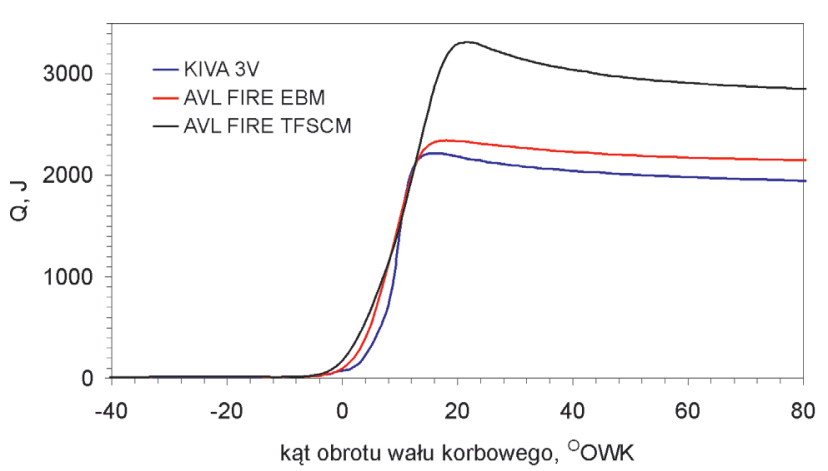

gramów obliczeniowych. W przypadku modelowania ze spalaniem przebiegi zmian ciśnienia dla programu KIVA -3V oraz FIRE z modelem spalania Eddy Breakup osiągnęły bardzo dużą zgodność natomiast model TFSC spowodował większą wartość maksymalną ciśnienia oraz przebieg spalania zachodził stosunkowo wolniej.

Na rysunku 5 przedstawiono przebieg wydzielania się ciepła oraz szybkość wydzielania się ciepła. Model spalania TFSC zastosowany w analizowanym przypadku charakteryzował się największym wydzielonym ciepłem a jednocześnie wydzielanie ciepła następowało w najdłuższym odcinku czasu. Model zastosowany w programie KIVA-3V charakteryzował się najmniejszym wydzielonym ciepłem a jednocześnie całe ciepło zostało wydzielone w najkrótszym czasie.

Energia kinetyczna turbulencji osiąga swoje maksimum w czasie rozprzestrzeniania się płomienia. Model w programie KIVA-3V charakteryzował się kilkukrotnie większą wartością maksymalną energii kinetycznej turbulencji.

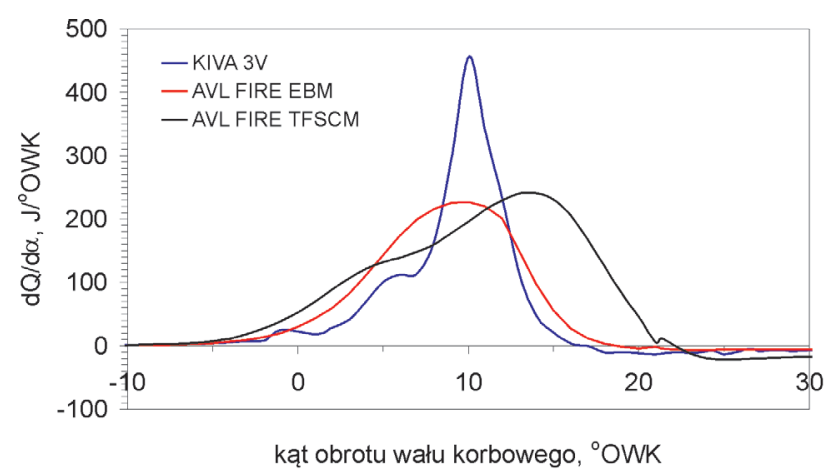

Fig. 5. Heat release and heat release rate Rys. 5. Wydzielone ciepło oraz szybkość wydzielania ciepła

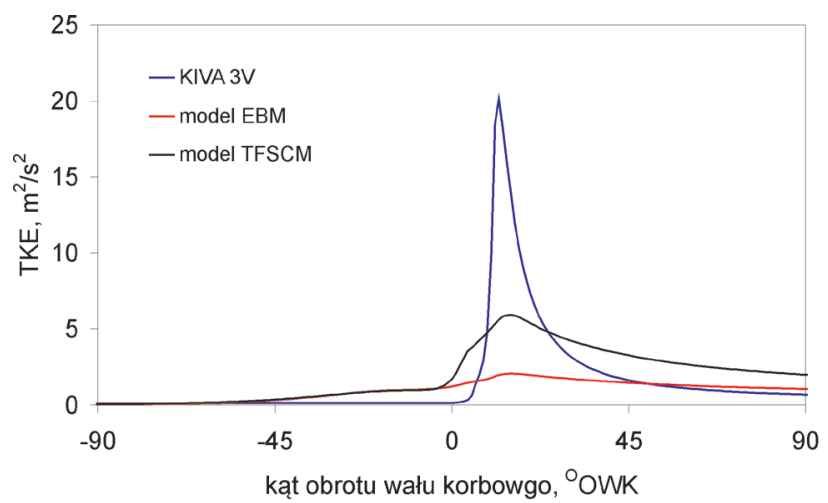

Fig. 6. Turbulent kinetic energy

Rys. 6. Energia kinetyczna turbulencji
The maximum value of turbulent kinetic energy was achieved during flame spread. The maximum value of turbulent kinetic energy obtained from KIVA-3V code has several time higher level then obtained from other models.

KIVA-3V code gave in this case the highest increase of pressure which in consequence had an influence on other parameters of thermal cycle. Maximum $\mathrm{dp} / \mathrm{d} \varphi$ gained the

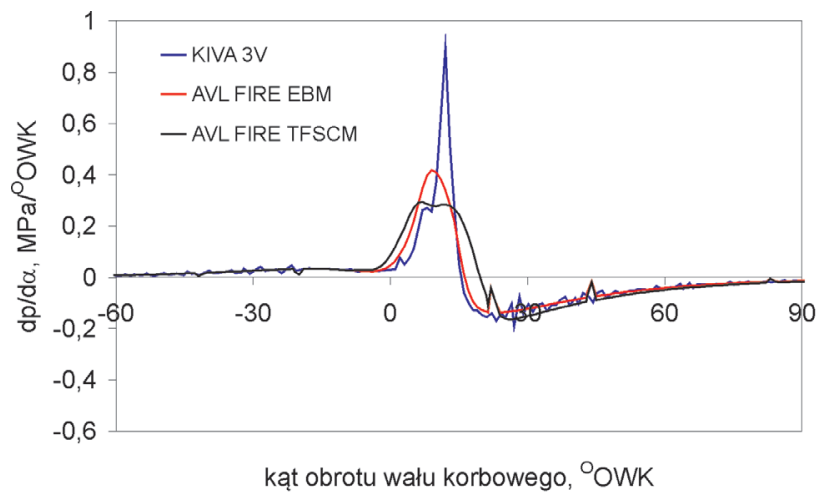

Rys. 7. Przyrost ciśnienia w funkcji kąta obrotu wału korbowego Fig. 7. Pressure growth speed courses in function of crank angle

Obieg cieplny silnika uzyskany programem KIVA-3V charakteryzował się największym przyrostem ciśnienia co miało w konsekwencji wpływ na pozostałe parametry charakteryzujące obieg. Maksimum dp/d $\varphi$ wynosiło $0,9 \mathrm{MPa} /{ }^{\circ} \mathrm{OWK}$ dla programu KIVA-3V, a najmniejszy przyrost ciśnienia osiągnięto dla modelu TFSC 0,3 $\mathrm{MPa} /{ }^{\circ} \mathrm{OWK}$. 


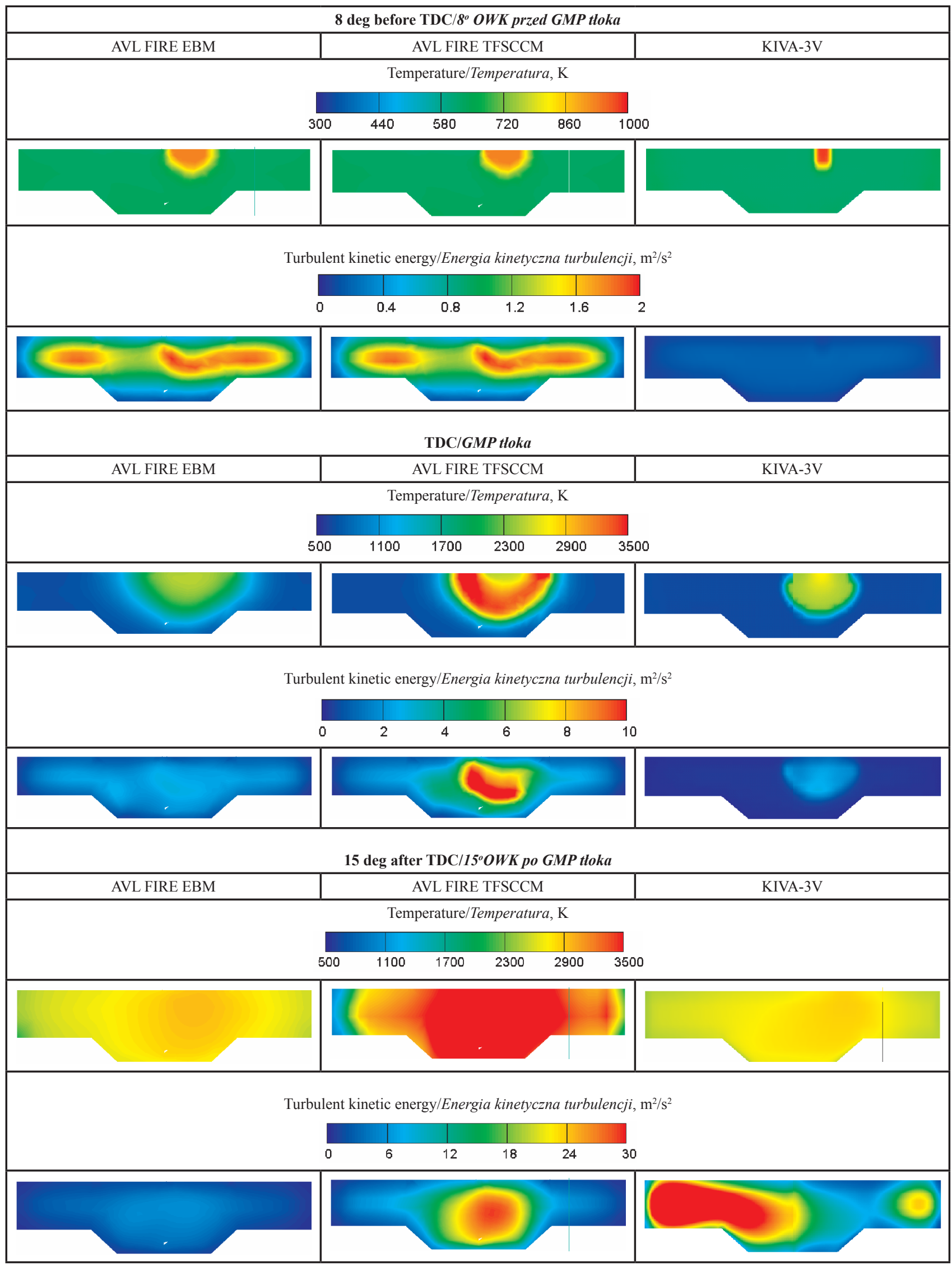

Fig. 8. Spatial distribution of temperature and turbulent kinetic energy in selected crank angles Rys. 8. Czasoprzestrzenny rozktad temperatury i energii kinetycznej turbulencji dla wybranych kątów OWK 
value of $0.9 \mathrm{MPa} / \mathrm{deg}$ in KIVA-3V code and the smallest increase in pressure was obtained from TFSC model 0.3 $\mathrm{MPa} / \mathrm{deg}$. Spatial distributions of temperature and turbulent kinetic energy in combustion chamber of test engine are presented on Fig. 8 .

\section{Conclusion}

Paper presents results of modelling gas engine thermal cycle using AVL FIRE and KIVA-3V software. There are described three combustion models used in software. KIVA and FIRE software are used in Institute of Internal Combustion Engines and Control Engineering for analysis of thermal cycle of IC engines. Comparison of modelling results of thermal cycle of IC engine is presented in paper. All used combustion models are dependent on turbulence of flow field before ignition. FIRE software gives many possibilities with many combustion models, but they require verification. Pressure, temperature, heat transfer and turbulence parameters variations in function of crank angle as well as spatial distribution of above mentioned quantities at selected crank angles were determined.

This same initial and boundary conditions were taken in all analysed cases. Results are different in respect of values and courses. Unfortunately this article did not include results from experiment. Comparison of modelling and experimental results will be presented in next paper.

Paper reviewed/Artykut recenzowany
Czasoprzestrzenny rozkład temperatury i energii kinetycznej turbulencji w komorze spalania silnika badawczego dla analizowanych modeli spalania pokazano na rys. 8 .

\section{Podsumowanie}

W pracy przedstawiono wyniki modelowania obiegu cieplnego silnika tłokowego przy pomocy dwóch programów komputerowych AVL FIRE oraz KIVA-3V, które należą do specjalistycznych kodów przeznaczonych do modelowani obiegu silnika spalinowego. Program KIVA-3V jest programem, który od szeregu lat wykorzystywany jest przez IMTiTS w badaniach silników tłokowych. Nowo pozyskany program FIRE jest obecnie jednym $z$ najnowocześniejszych narzędzi numerycznych zawierających szereg zaawansowanych czasoprzestrzennych podmodeli procesu tworzenia i spalania mieszanki palnej w silniku tłokowym. W rezultacie modelowania FIRE i KIVA otrzymano szereg wielkości charakteryzujących proces spalania w silniku badawczym, które byłyby bardzo trudne do uzyskania drogą pomiarów. Pomimo, że wszystkie modelowane przypadki charakteryzowały się takimi samymi warunkami brzegowymi i początkowymi, wyniki analizy dla poszczególnych modeli nie są jednakowe i różnią się zarówno co do wartości jak i przebiegu w zależności od kąta obrotu wału korbowego.

Niestety prezentowany artykuł nie zawiera wyników badań empirycznych, dlatego nie jest możliwa właściwa ocena zastosowanych modeli procesu spalania. Kolejne prace powinny w oparciu o pomiary stanowiskowe na hamowni dokonać weryfikacji modeli zastosowanych w programie AVL FIRE.

silnikowe. International Scientific Conference on Internal Combustion Engines KONES'93, Gdańsk - Jurata, 1993.

[7] Szwaja S., Jamrozik A.: Analysis of Combustion Knock in the SI Engine. Silniki Spalinowe/Combustion Engines, Mixture Formation Ignition \& Combustion, Nr 2009-SC2, June 2009.

[8] Tutak W., Jamrozik A., Kociszewski A., Sosnowski M.: Experimental Research into Turbulence Field in Combustion Chamber of Internal Combustion Engine. Journal of KONES Powertrain and Transport, Vol. 13, No. 2, European Science Society of Powertrain and Transport Publication, Warsaw 2006.

[9] Tutak W.: Thermal cycle of SI engine modeling with initial swirl process into consideration, Combustion Engines, 1/2008 (132), 2008.

[10] Tutak W.: Modelling of Flow Processes in the Combustion Chamber of IC Engine. MEMSTECH'2009. Proceedings of the 5th International Conference MEMSTECH'2009. Perspective Technologies and Methods in Mems Design. Lviv - Polyana, Ukraine. s. 45-48, 2009.

[11] Warnatz J., Maas U., Diable R.W.: Combustion. Physical and Chemical Fundamentals, Modeling and Simulation, Experiments, Pollutant Formation. Springer, 2006.

[12] www.avl.com

Mr. Arkadiusz Jamrozik, DEng. - doctor in the Faculty of at Czestochowa University of Technology.

Dr inż. Arkadiusz Jamrozik - adiunkt na Wydziale Inżynierii Mechanicznej i Informatyki Politechniki Częstochowskiej.

e-mail: jamrozik@imtits.pcz.czest.pl

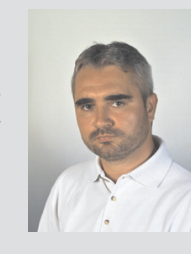

of at Czestochowa University of Technology.

Dr inż. Wojciech Tutak - adiunkt na Wydziale Inżynierii Mechanicznej i Informatyki Politechniki Częstochowskiej.

e-mail:tutak@imc.pcz.czest.pl

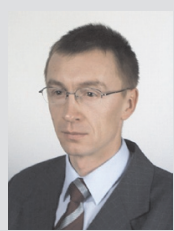

